\title{
PEMBERDAYAAN MASYARAKAT MELALUI ZAKAT INFAQ SHADAQOH WAKAF (ZISWAF) DALAM MENINGKATKAN EKONOMI MASYARAKAT
}

\section{COMMUNITY EMPOWERMENT THROUGH ZAKAT INFAQ SHADAQOH WAKAF (ZISWAF) IN IMPROVING COMMUNITY EKONOMY}

\author{
T M Sahri 1a, M Paramita1
}

${ }^{1}$ Program Studi Ekonomi Syariah, Fakultas Ekonomi Islam Universitas Djuanda Bogor
aKorespondensi: Tsania Maulida Sahri; E-mail: Tsaniamaulidasahri@unida.ac.id
(Diterima: 07-08-2020; Ditelaah: 08-08-2020; Disetujui: 09-09-2020)

\begin{abstract}
The problem of Padamulya Village community is that people do not understand about Zakat, Infaq, Sadaqoh, and Waqf (ZISWAF), the community thinks that zakat is only on zakat fitrah and zakat maal in general, the community cannot distinguish between income already affected by zakat or still merely infaq, as well as alms, and there has been no grouping of the receipt of benefits from the collection of Zakat, Infaq, Sadaqoh, Wakaf (ZISWAF) funds. And distribution is not yet programmed (planned and measured) according to the rules in the Qur'an and the Hadith. The aim in the implementation of Community Service (PKM) in Padamulya Village, Pasirkuda District, Cianjur Regency is oriented to community development, achievement of planned socialization programs, enhancing community capacity in the economic field, namely on Zakat, Infaq, Shadaqoh, Wakaf (ZISWAF). The method is carried out in a participatory manner through lecture, question and answer methods and discussion on increasing knowledge about Zakat, Infaq, Sadaqoh, Waqf (ZISWAF). As for the results of the socialization activities of Zakat, Infaq, Sadaqoh, Waqf (ZISWAF) is the understanding of the people who do not know yet become know. The implementation of this socialization activity showed that there was an increase in public knowledge about the importance of Zakat, Infaq, Shodaqoh, and Waqf (ZISWAF) in improving the economy of the community especially in Padamulya Village.

Keywords : Socialization, Islamic Economy, ZISWAF, Padamulya Village.
\end{abstract}

\begin{abstract}
ABSTRAK
Adapun permasalahan masyarakat Desa Padamulya adalah masyarakat belum memahami mengenai Zakat, Infaq, Shadaqoh, dan Wakaf (ZISWAF), masyarakat beranggapan bahwa zakat hanya ada pada zakat fitrah dan zakat maal secara umum saja, masyarakat tidak dapat membedakan penghasilan sudah terkena zakat atau masih sekedar infak, serta sedekah, dan belum adanya pengelompokkan penerimaan manfaat dari penghimpunan dana Zakat, Infaq, Shadaqoh, Wakaf (ZISWAF). Serta belum terlaksananya pendistribusian secara terprogram (terencana dan terukur) sesuai aturan yang ada di Al-Qur'an dan Hadist. Tujuan dalam pelaksanaan Pengabdian Kepada Masyarakat (PKM) di Desa Padamulya Kecamatan Pasirkuda Kabupaten Cianjur berorientasi pada pengembangan masyarakat, pencapaian program sosialisai yang telah direncanakan, peningkatan kemampuan masyarakat dalam bidang ekonomi yaitu tentang Zakat, Infaq, Shadaqoh, Wakaf (ZISWAF). Metode yang dilakukan secara partisipatif dengan metode ceramah, tanya jawab dan diskusi peningkatan pengetahuan tentang Zakat, Infaq, Shadaqoh, Wakaf (ZISWAF). Adapun hasil dari kegiatan
\end{abstract}


sosialisasi Zakat, Infaq, Shadaqoh, Wakaf (ZISWAF) adalah pemahaman masyarakat meningkat yang belum mengetahui menjadi tahu. Pelaksanaan kegiatan sosialisasi ini menunjukan bahwa adanya peningkatan pengetahuan masyarakat tentang pentingnya Zakat, Infaq, Shodaqoh, dan Wakaf (ZISWAF) dalam meningkatkan perekonomian masyarakat yang khususnya di Desa Padamulya.

Kata Kunci : Sosialisasi, Ekonomi Islam, ZISWAF, Desa Padamulya.

Sahri, T. M., \& Paramita, M. (2019).Pemberdayaan Masyarakat Melalui Zakat Infaq Shadaqoh Wakaf (Ziswaf) Dalam Meningkatkan Ekonomi MAsyarakat. Jurnal Qardhul Hasan : Media Pengabdian kepada Masyarakat, 5(2), 121-126.

\section{PENDAHULUAN}

Salah satu sektor ekonomi syariah yang didalamnya berperan pada bidang sosial adalah melalui instrument ZISWAF (Zakat, Infaq, Shadaqah, Wakaf). (Syafiq, 2017) Melalui pengelolaan yang optimal, ZISWAF berpotensi besar mengatasi berbagai permasalahan bangsa, baik ekonomi maupun sosial. Zakat, Infaq, Shadaqah, Wakaf adalah ibadah yang memiliki dua dimensi, yaitu merupakan ibadah sebagai bentuk ketaatan kepada Allah dan kewajiban berhubungan baik terhadap sesama manusia yang dapat mewujudkan slogan bahwa umat muslim bersaudara, saling tolong menolong antara yang kuat dengan yang lemah atau yang kaya dengan yang miskin dalam tatanan kehidupan sosial. (Kasdi, 2016) Zakat, Infaq, Shadaqah, Wakaf merupakan salah satu ciri dari sistem ekonomi Islam, karena implementasi azas keadilan dalam sistem ekonomi Islam. (Khurul Aimmatul Ummah, 2018)

Pada pelaksanaan Pengabdian Masyarakat yang dilaksanakan berlokasi di Desa Padamulya Kecamatan Pasirkuda Kabupatan Cianjur. Ditinjau dari agama yang dianut, sebagian besar masyarakat Desa Padamulya beragama Islam dan dengan berbagai profesi penduduknya, maka potensi ZISWAF seharusnya bisa mencapai optimal. Tetapi masih banyak diantara masyarakat yang tidak mengetahui ketentuan-ketentuan ZISWAF dan apa saja manfaat dari ZISWAF, seperti masyarakat hanya beranggapan bahwa wakaf hanya ada pada wakaf tanah saja dan biasanya wakaf diperuntukkan untuk tempat ibadah. Selain itu belum banyaknya masyarakat Desa Padamulya yang memahami ketentuan dan teknis pembayaran zakat maal, masyarakat tidak dapat membedakan penghasilan sudah terkena zakat atau masih sekedar infak, serta sedekah. Sebagian merekapun bingung cara membayar zakatnya. Masyarakat Di Desa Padamulya ini hanya memprioritaskan zakat fitrah setiap tahunnya. (Sukmadewi, 2017)

Berdasarkan hal tersebut, masyarakat Desa Padamulya membutuhkan pemahaman mengenai Zakat, Infaq, Shodaqoh, dan Wakaf (ZISWAF). Oleh karena itu, dengan program sosialisasi Zakat, Infaq, Shodaqoh, dan Wakaf (ZISWAF) diharapkan dapat memberikan kesadaran kepada masyarakat tentang pentingnya Zakat, Infaq, Shodaqoh, dan Wakaf (ZISWAF) dalam meningkatkan perekonomian masyarakat yang khususnya di Desa Padamulya.

Penempatan mahasiswa sebagai fasilitator/khaadimul ummah juga dilakukan oleh Fakultas Ekonomi Islam Universitas Djuanda melalui kegiatan "Pengabdian Kepada Masyarakat (PKM) dengan adanya program sosialisasi Ekonomi Syariah". Dengan kegiatan tersebut merupakan salah satu program yang memiliki harapan agar segala permasalahan ekonomi masyarakat dari kalangan menengah kebawah dapat tersatasi melalui tingkat kesadaran masyarakat Desa Padamulya terhadap pentingnya Zakat, Infaq, Shadaqah, dan Wakaf (ZISWAF).

Dengan demikian, pelaksanaan Pengabdian Kepada Masyarakat (PKM) Fakultas Ekonomi Islam 2019 di Desa Padamulya 
selain menjadi tantangan bagi mahasiswa untuk mengaplikasikan ilmu pengetahuan yang telah diperoleh di tengah-tengah masyarakat, juga dapat membantu masyarakat Desa Padamulya untuk mengembangkan potensi yang dimilikinya. Tantangan bagi mahasiswa Fakultas Ekonomi Islam Universitas Djuanda adalah bagaimana mengaplikasikan ilmu pengetahuan ekonomi Islam di tengahtengah masyarakat Desa Padamulya yang dapat memberikan dampak positif terhadap masyarakat, terutama dibidang ekonomi Islam.

\section{MATERI DAN METODE}

Pelaksanaan kegiatan dimulai dengan persiapan mencari materi yang akan dibahas lalu survey awal untuk melihat kondisi kesiapan responden di lapangan dan sosialisasi. Responden dalam kegiatan ini terdiri atas Ibu-ibu pengajian dan PKK di dusun Lingkungsari, seluruh yang hadir dalam kegiatan sosialisasi berjumlah 45 orang. Pelaksanaan kegiatan ini menggunakan metode Pendekatan Orang Dewasa (POD) yang dilakukan secara partisipatif dengan metode ceramah, tanya jawab dan diskusi peningkatan pengetahuan tentang Zakat, Infaq, Shadaqoh, Wakaf (ZISWAF).

\section{HASIL DAN PEMBAHASAN}

Kegiatan sosialisasi ini dihadiri oleh 43 Orang. Kegiatan ini dilakukan di Masjid Darussalam Dusun Lingkungsari Desa Padamulya Pukul 13.00 WIB. Materi yang disampaikan pada kegiatan sosialisasi ini adalah Peran Zakat, Infaq, Shodaqoh, Wakaf (ZISWAF) dalam meningkatkan Ekonomi Masyarakat.

Adapun hasil dari kegiatan sosialisasi Zakat, Infaq, Shadaqoh, Wakaf (ZISWAF) adalah sebagai berikut: Ibu-ibu setelah dilakukan sosialisasi pemahaman tentang ekonomi syariah telah memahami materi apa yang disampaikan meskipun memang belum pada tahap memahami yang secara detail.

Pada saat sosialisasi pemahaman masyarakat meningkat yang belum mengetahui menjadi tahu.

Setelah pemaparan dilakukan diskusi dan tanya jawab masyarakat dapat memahami materi yang dibahas dengan mengajukan pertanyaan dan sharing mengenai yang dibahas dan masyarakat antusias menyampaikan berbagai pertanyaan.

Pemahaman terhadap masyarakat mengenai apa perbedaan antara zakat, infak, sedekah dan wakaf serta memberi pemahaman bagaimana majunya peradaban Islam terdahulu karena pengelolaan instrumen-instrumen keuangan publiknya, beberapa diantaranya ialah ZISWAF (Zakat, Infak, Sedekah dan Wakaf). Sehigga dengan pemahaman tersebut masyarakat akan menimbulkan rasa peduli serta ingin berkontribusi melalui beberapa instrumen keuangan publik islam tersebut.

Selain hasil nonfisik pada kegiatan sosialisasi ini, ada juga hasil fisik dalam program sosialisasi ZISWAF yaitu berbentuk Modul yang berjudul "Peran Zakat, Infaq, Shodaqoh, Wakaf (ZISWAF) dalam meningkatkan Ekonomi Masyarakat".

\section{PELAKSANAAN KEGIATAN}

program sosialisasi ini dilaksanakan 1 (satu) kali di Masjid Darussalam pada tanggal 23 Agustus 2019 yaitu disaat pengajian rutin yang biasa dilaksanakan oleh ibu-ibu di Dusun Lingkungsari. Kegiatan sosialisasi ini dilaksanakan dengan pemaparan materi kepada Ibu-ibu pengajia Majlis Ta'lim Darussalam. Jumlah masyarakat yang hadir dalam kegiatan Sosialisasi ZISWAF ini ada 43 Orang. Melihat kondisi lokasi kegiatan Sosialisasi dengan peralatan yang seadanya, oleh karena itu pemateri tidak menggunakan mikrofon pada saat menyampaikan materi, dan tidak menggunakan Infocus yang seharusnya dapat menampilkan materi sosialisasi dan proses kegiatan sosialisasi terlihat hidup dan bervariasi. 
Setelah materi selesai dipaparkan, dilanjutkan dengan diskusi berupa tanya jawab antara pemateri dengan masyarakat. Diskusi dilakukan agar masyarakat lebih memahami materi yang telah disampaikan. Melalui diskusi, sosialisasi tidak hanya sekedar transfer knowledge saja melainkan dapat sharing pengalaman maupun permasalahan yang sedang dihadapi oleh masyarakat.

\section{SOSIALISASI ZISWAF}

Sosialisasi ini dimaksudkan supaya masyarakat Dusun Lingkungsari dapat mengetahui pentingnya ZISWAF dalam meningkatkan kesadaran masyarakat terhadap pentingnya peran Zakat, Infaq, Shadaqoh dan Wakaf terhadap perekonomian masyarakat. Dalam sosialisasi tentunya harus melalui tahapantahapan, yaitu memahami kondisi masyarakat, permasalahan yang ada dimasyarakat dan perlu adanya pemateri yang telah menguasai materi yang ingin disampaikan dan mencoba meluaskan jaringan para masyarakat dengan menjelaskan tentang ZISWAF terutama peran Zakat, Infaq, Shodaqoh, Wakaf (ZISWAF) dalam meningkatkan Ekonomi Masyarakat. apabila dukungan telah ada, maka perlu berkonsultasi dengan tokohtokoh masyarakat setempat yang berpengaruh, baik yang formal maupun informal. Kemudian setelah mempersiapkan materi dilanjut konsep acara, lalu melaksanakan persiapan-persiapan sarana yang diperlukan dan mulailah melaksanakan kegiatan sosialisasi ZISWAF.

\section{EVALUASI DAN MONITORING}

Indikator keberhasilan kegiatan ini adalah keseriusan dari peserta mengikuti partisipasi dalam kegiatan sosialisasi. Sebagian besar peserta aktif mengikuti seluruh kegiatan dari awal pemaparan sosialisasi kemudian tanya jawab dan diskusi. Pendekatan dengan cara bertatap muka langsung memberi kesempatan yang lebih banyak kepada para peserta untuk melakukan diskusi dan saling bertukar informasi. Adapun Fungsi Monitoring sebagai berikut: Compliance (kesesuaian/kepatuhan) menentukan kesesuaian implementasi kebijakan dengan standard dan prosedur yang telah ditentukan; Auditing (pemeriksaan) menentukan ketercapaian sumbersumber/pelayanan kepada kelompok sasaran (target groups). Adapun indikator ketidak capaian dari kegiatan sosialisasi ini yaitu Kurangnya fasilitas seperti Infocus yang seharusnya dapat menampilkan materi sosialisasi dan proses kegiatan sosialisasi terlihat jelas, hidup dan bervariasi. Juga tidak menggunakan microphone pada saat penyampaian materi dikarenakan kurangnya ketersediaan barang-barang; Tidak tersealisasikan acara sosialisasi ZISWAF ini dilaksanakan dalam bentuk seminar karena kegiatan sosialisasi lebih efektif jika dilakukan ketika pengajian karena jadwal pengajian sudah pasti dan banyaknya masyarakat yang rutin hadir dalam pengajian dan kegiatan sosialisasi dilakukan lebih dari 1 kali, karena keterbatasan waktu yang tidak memungkinkan. Adanya Evaluasi berhubungan dengan hasil informasi tentang nilai serta memberikan gambaran tentang manfaat suatu kebijakan/program.

\section{INDIKATOR HASIL DAN MANFAAT}

Hasil dan manfaat dari pelatihan ini antara lain para masyarakat sudah memiliki peningkatan pengetahuan tentang ZISWAF. Setelah mendapat pemaparan melalui metode ceramah, berdasarkan hasil monitoring dan evaluasi peserta telah mengetahui tentang ZISWAF.

Tabel 1. Capaian

\begin{tabular}{|l|l|l|}
\hline Capaian & Sebelum & Sesudah \\
\hline $\begin{array}{l}\text { perbedaan } \\
\text { Zakat, Infaq, } \\
\text { Shadaqoh } \\
\text { dan Wakaf } \\
\text { (ZISWAF) }\end{array}$ & $50 \%$ & $80 \%$ \\
\hline $\begin{array}{l}\text { Perbedaan } \\
\text { penghasilan } \\
\text { sudah } \\
\text { terkena zakat }\end{array}$ & $40 \%$ & $70 \%$ \\
\hline
\end{tabular}




\begin{tabular}{|l|l|l|}
\hline $\begin{array}{l}\text { atau masih } \\
\text { sekedar } \\
\text { infak, serta } \\
\text { sedekah }\end{array}$ & & \\
\hline $\begin{array}{l}\text { Jenis-jenis } \\
\text { Wakaf. }\end{array}$ & $30 \%$ & $70 \%$ \\
\hline $\begin{array}{l}\text { kesadaran } \\
\text { masyarakat } \\
\text { terhadap }\end{array}$ & $50 \%$ & $80 \%$ \\
pentingnya \\
peran Zakat, \\
Infaq, \\
$\begin{array}{l}\text { Shadaqoh } \\
\text { dan Wakaf } \\
\text { terhadap } \\
\text { perekonomia } \\
\text { n masyarakat }\end{array}$ & & \\
\hline
\end{tabular}

\section{MASALAH YANG DIHADAPI}

Masalah yang dihadapi dari kegiatan ini adalah kurangnya fasilitas pendukung dalam berjalannya kegiatan sosialisasi seperti dari segi sarana prasarana, kemudian masih banyaknya masyarakat yang mempunyai kegiatan yang lain seperti bertani, sehingga belum dapat mengikuti kegiatan sosialisasi. Dan disisi lain masih kurangnya motivator dalam membimbing masyarakat untuk kedepannya, Karena itu dikhawatirkan tidak berlanjutnya kegiatan sosialisasi ZISWAF dikemudian hari. Saat ini sosialisasi masih hanya di wilayah sekitar desa padamulya, apabila ingin menjangkau ke seluruh wilayah harus menggunakan teknologi informasi sehingga semua kalangan dimanapun berada dapat menjangkau kegiatan sosialisasi ini. Tetapi apabila menggunakan teknologi informasi rata-rata masyarakat harus dapat mempunyai sarana elektronik. Sementara sarana elektronik tidak semuanya mengerti dan memiliki kemampuan bagaimana menggunakan teknologi tersebut terutama para ibu-ibu dan yang sudah lanjut usia.

\section{KESIMPULAN}

Adapun hasil dari kegiatan sosialisasi Zakat, Infaq, Shadaqoh, Wakaf (ZISWAF) adalah sebagai berikut:
Ibu-ibu setelah dilakukan sosialisasi pemahaman tentang ekonomi syariah telah memahami materi apa yang disampaikan meskipun memang belum pada tahap memahami yang secara detail.

Pada saat sosialisasi pemahaman masyarakat meningkat yang belum mengetahui menjadi tahu. Setelah pemaparan dilakukan diskusi dan tanya jawab masyarakat dapat memahami materi yang dibahas dengan mengajukan pertanyaan dan sharing mengenai yang dibahas dan masyarakat antusias menyampaikan berbagai pertanyaan.Pemahaman terhadap masyarakat mengenai apa perbedaan antara zakat, infak, sedekah dan wakaf serta memberi pemahaman bagaimana majunya peradaban Islam terdahulu karena pengelolaan instrumen-instrumen keuangan publiknya, beberapa diantaranya ialah ZISWAF (Zakat, Infak, Sedekah dan Wakaf). Sehigga dengan pemahaman tersebut masyarakat akan menimbulkan rasa peduli serta ingin berkontribusi melalui beberapa instrumen keuangan publik islam tersebut.

Selain hasil nonfisik pada kegiatan sosialisasi ini, ada juga hasil fisik dalam program sosialisasi ZISWAF yaitu berbentuk Modul yang berjudul "Peran Zakat, Infaq, Shodaqoh, Wakaf (ZISWAF) dalam meningkatkan Ekonomi Masyarakat".

\section{UCAPAN TERIMAKASIH}

BELUM .

\section{DAFTAR PUSTAKA}

Kasdi, A. (2016). Filantropi Islam Untuk Pemberdayaan Ekonomi Umat (Model Pemberdayaan ZISWAF di BMT SeKabupaten Demak) . IQTISHADIA, Volume 9 Nomor 2, Pp 15

Sukmadewi, Y. D. (2017). Sosialisasi Legalitas dan Manajemen Usaha Bagi Pelaku Usaha UMKM di Kecamatan 
Pedurungan. Semarang : Prodi Manajemen, Fakultas Ekonomi,

Syafiq,

A. (2017). PENINGKATAN KESADARAN MASYARAKAT DALAM MENUNAIKAN ZAKAT, INFAQ, SEDEKAH DAN WAKAF (ZISWAF). Jurnal Ekonomi Islam, Volume 2 Nomor 1, Pp 15.
Khurul Aimmatul Ummah, A. R. (2018). Pola Implementasi Alokasi ZISWAF Dalam Penyediaan Akses Pendidikan Bagi Kaum Dhuafa. Jurnal Ekonomi dan Bisnis Islam, Volume 3 Nomor 2, Pp25. 